Egyptian

Orthodontic Journal

\title{
CT EVALUATION OF MANDIBULAR SYMPHYSIS IN DIFFERENT VERTICAL AND ANTERO-POSTERIOR JAW RELATIONSHIPS
}

\author{
Atia Abd Elwareth Abd Elrazik Yousif ${ }^{1}$, \\ Hussein Ibrahim Aly Saudi ${ }^{2}$
}

\section{ABSTRACT:}

Introduction: The mandibular symphysis (MS) morphology results from the interplay of different genetic, non-genetic, vertical jaw relationships, inclination of the lower incisors and adaptive factors. The thickness of the alveolar process at the mandibular symphysis can be influenced by the facial growth pattern so the present study was designed to evaluate the (MS) dimensions in different vertical and horizontal jaws relationships. Material and Methods: A sample of 120 patients with age range from 11 to 13 years was divided into 6 groups according to $A \mathcal{N} B$ angle and $S \mathcal{N}$

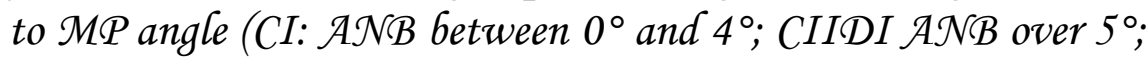
CIII below $0^{\circ}$. Hypo-divergent: $S \mathcal{N}$ to $\mathcal{M p}$ less than 29․ Hyperdivergent $S \mathcal{N}$ to $\mathcal{M p}$ more than $36^{\circ}$ ). For each patient a CT of $\mathcal{M} S$ in the mid-sagittal plane was taken: (MS) widths, height and different inclination angles were measured by the CT machine integrated program. Results: hyper-divergent growth pattern showed highly significant differences between Class I, Class IID1 and Class III regarding perpendicular distance from $\mathrm{Pg}$ point to $I d-M e$ line and the anterior inclination angles of the symphysis with Class III showed greater values than Class I and Class IID1

1- Lecturer of Orthodontic, orthodontic department, Faculty of Dentistry, Tanta University, Egypt.

2- Professor and head of department of oral medicine, periodontology, diagnosis and radiology, Faculty of Dentistry, Tanta University, Egypt. 
Egyptian

Orthodontic Journal

while the middle symphysial width showed high significant difference between Class I and (Class IID1, Class III). Hypo-divergent growth pattern showed high significant differences between Class I, Class IID1 and Class III regarding perpendicular distance from $\mathrm{Pg}$ point to Id-M Me line and the anterior inclination angles of the symphysis with Class IID1 showed the lowest values for the inclination angles while Class I showed the shortest distance from $\mathrm{Pg}$ point to Id-MMe line. Conclusion: Significant differences were found between hypo and hyper divergent growth patterns regarding all $\mathcal{M S}$ dimensions except Id-B distance and upper symphysial width (Id-Id1) and Class III showed the greater inclination angles than Class I and Class IID1.

\section{INTRODUCTION}

Mandibular symphysis (MS) morphology has an impact on diagnosis and treatment planning in orthodontic patients; it serves as a reference anatomical landmark for esthetics and beauty of the face in general and of the lower part in particular ${ }^{(1,2)}$

MS is morphologically divided into two regions, the dento-alveolar and basal symphysIs. ${ }^{(3)}$ The MS width contributes to the outline of the face, particularly the profile, in addition to being a reference for the position of the incisors by the degree of its protrusion. ${ }^{(4)}$

MS morphology is a complex phenotype that results from the interplay of different genetic, non-genetic, and adaptive factors ${ }^{(5,6)}$ Functional environment has been claimed to affect the shape and size of MS, such that MS demonstrates an adaptive morphological response to the bio-mechanical loads experienced at various points in the masticatory cycle $^{(7,8)}$.

It is known that the facial growth pattern influences not only the morphology of the MS, but also the thickness of the alveolar process in this area, and consequently, the position of the mandibular incisors. The 
Egyptian

Orthodontic Journal

wider the symphysis, the greater the possibility to tip forwards the mandibular incisors. ${ }^{(9)}$ Moreover, one speculates that the negative vertical overlap is another factor influencing the symphysis morphology ${ }^{\cdot(10)}$

MS is an anatomical structure of the mandible in which the lower incisors are found including the anterior portion of the chin. MS contributes to the composition and balance of facial harmony and must be considered when deciding on orthodontic treatment in borderline cases $^{\cdot(11-14)}$ Class II malocclusions are characterized by a retrognathic mandible or a prognathic maxilla with variable vertical dimensions.

Excessive vertical development were emphasized in Class II malocclusions by numerous research groups. ${ }^{(15-17)}$ Schudy ${ }^{(18)}$ focused on the term facial divergence and two extremes of it would be hypo-divergence and hyper-divergence. Although various measurements have been used to classify vertical divergence of malocclusion, mandibular plane angle is one of the basic parameters. ${ }^{(16,18,19)}$

Björk and Skieller ${ }^{(20)}$ in their longitudinal implant studies have described remodeling pattern of MS; apposition below the symphysis and at its posterior surface in forward rotating mandibles and, apposition at the anterior surface and resorption at the lower surface of the symphysis with apposition at its inner surface in backward rotating cases

Similarly Ricketts ${ }^{(21)}$ stated that symphysis morphology may be used to predict the direction of mandibular growth. Björk ${ }^{(22)}$ also defined the inclination of MS is one of the seven signs for identification of the mandibular growth. The symphysis is also characterized as a growth zone, active in mandibular growth in width as well as in length, during the first half of the prenatal period, and the knowledge of mandibular growth is highly beneficial in diagnosis and treatment planning. ${ }^{(23)}$

Enlow noted that MS is one of the most variable areas in the entire mandible as seen among the different basic facial types and patterns 
Egyptian

Orthodontic Journal

divided into three subgroups according to their vertical morphology (MP-SN angle) as: Hypo-divergent (MP-SN angle $\leq 27^{\circ}$ ); Normo-divergent $\left(28^{\circ}\right.$ to $\left.37^{\circ}\right)$, and Hyper-divergent $\left(\geq 38^{\circ}\right)$. $^{(24)}$

Therefore, any variation of point B in the different skeletal patterns would affect the involved angular measurements. Additionally, point B has been used to measure a dento-alveolar parameter when it represents the demarcation between dento-alveolar and skeletal structures. ${ }^{(25)}$

There is an obvious correlation between mandibular growth rotation and the MS morphology, which have been shown by several research groups and may be used to predict the direction of mandibular growth. ${ }^{(20,21,22,23)}$

Class III malocclusions are believed to be the result of excessive growth of the mandible with respect to the maxilla and/or cranial base Sugawara and Mitani ${ }^{(26)}$, but Karlsen ${ }^{(27)}$ noted that mandibular skeletal protrusion was associated with forward positioning of the mandible relative to the anterior cranial base, and this may yield a Class III relationship without involving any morphological changes of the mandible.

Although anterior displacement of the mandible may play a part it is unclear whether Class III malocclusion is caused by variations in mandibular position, mandibular size, or a combination of the two Kerr et al ${ }^{(28,29)}$ so the aim of the present research was to evaluate and compare the thickness, height and inclination angle of the alveolar process of the MS with different facial patterns and different antero-posterior jaw relationships.

\section{MATERIAL AND METHODS}

A computerized tomography take for the MS at the mid sagittal plane for a sample of 120 female patients, with ages ranged from 11 to 13 years. The sample was divided into 3 groups with 40 patients in each group depending on ANB angle: 
- Class1: ANB between $0^{\circ}$ and $4^{\circ}$

- Class II D1 ANB over $5^{\circ}$

- Class III ANB below $0^{\circ}$

Each group further divided into two subgroups with 20 patients in each subgroup depending on SN to MP angle:

- Hypo-divergent: SN to Mp less than $29^{\circ}$

- Hyper-divergent SN to Mp more than $36^{\circ}(4,30)$

The following linear and angular MS parameters were measured by the CT machine integrated program (Figure 1and 2):

1- Id - B: from infra-dentale to supra-mentale

2- B - Pg: from subspinale to pogonion

3- $\mathrm{Pg}-\mathrm{Me}$ : from pogonion to menton

4- Id - Me: from infra-dentale to the most inferior point in the symphysis contour in the mid line

5- Pg perpendicular to Id-Me:

6- Id - Id 1: from infra-dentale which is the most superior point of the symphysis buccally in the mid line to a similar point lingually

7- B - B1: from supra-mentale to similar point in the lingual contour of the symphysis

8- Pg - Pg1: from the highest point of the buccal contour of the symphysis to the highest point on the lingual contour of the symphysis.

9- B - B1 - Gn: angle formed by supra-mentale , supra-mentale lingual and gnathion.

10- B - Pg - Me: angle formed by supra-mentale, pogonion and menton. 
11- Id - B -Pg: angle formed by infra-dentale, supra-mentale and pogonion.

12- B - Pg - Mp: angle formed by supra-mentale, pogonion and mandibular plane.

13- Id - B - Mp: angle formed by infra-dentale, supra-mentale and mandibular plane.

All obtained results were statistically analyzed to evaluate and correlate the thickness and different inclinations of the alveolar process of the mandibular symphysis with the facial pattern and different types of antero-posterior jaws relationships.

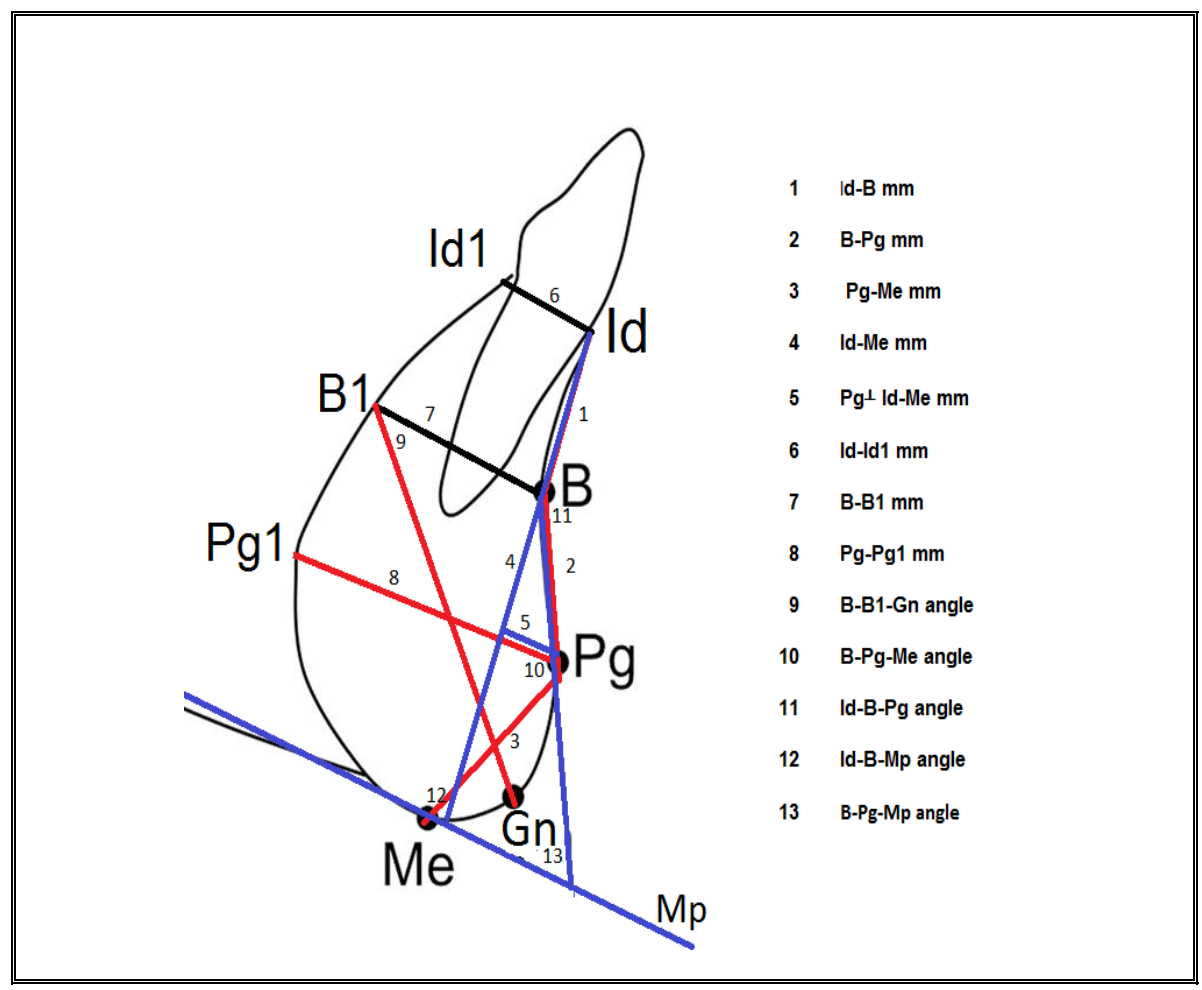

Figure (1): diagram showing linear and angular measurements of the mandibular symphysis 


\section{Egyptian \\ Orthodontic Journal}

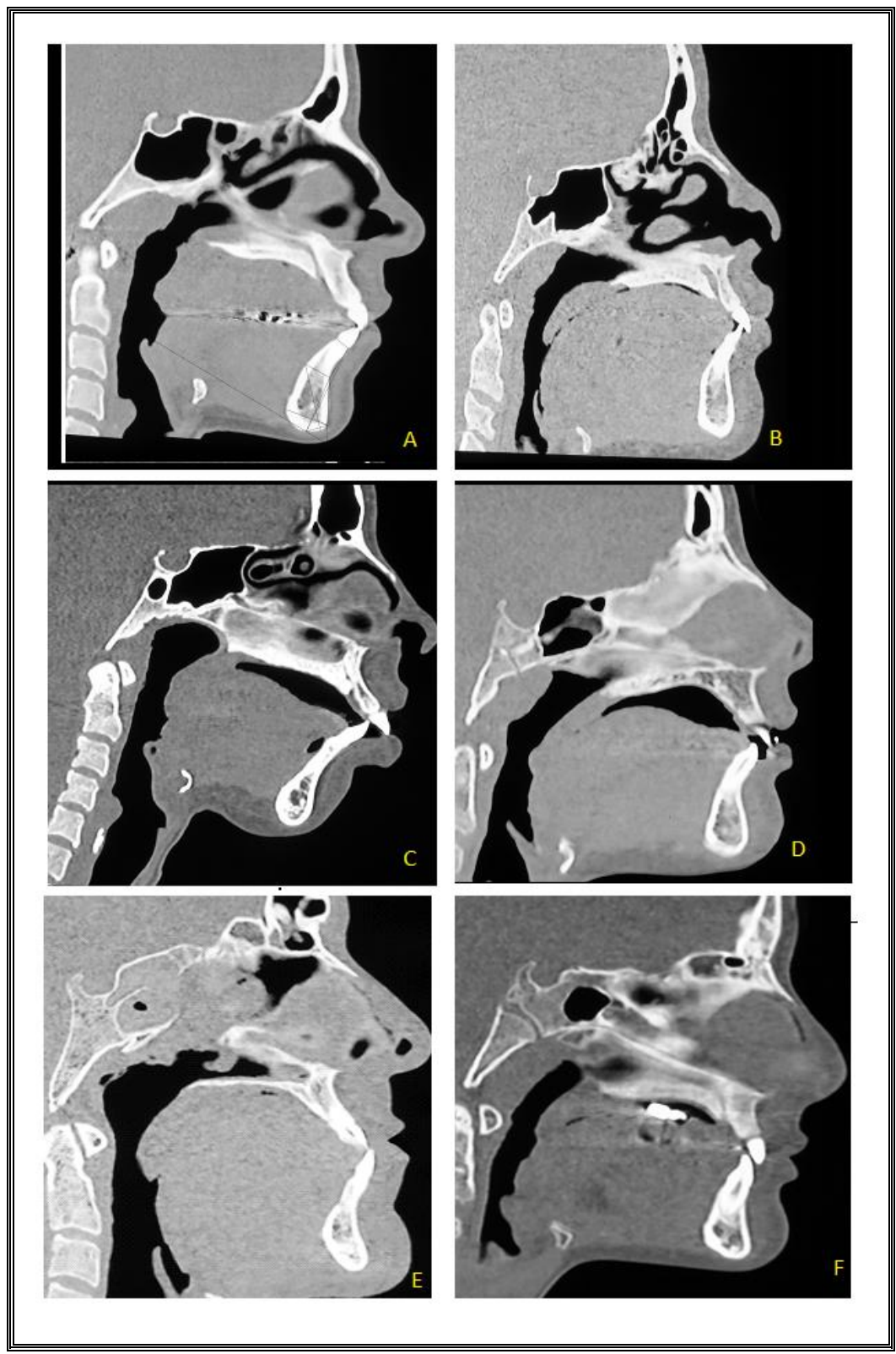

Figure (2): $\mathrm{CT}$ scan of the mandibular symphysis in the mid sagittal plane: A:CI hyper-divergent, B:CI hypo-divergent, C:CIID1 hyper-divergent, D:CIID1 hypo-divergent, E:CIII hyper-divergent, F:CIII hypo-divergent. 
Egyptian

Orthodontic Journal

\section{RESULTS}

No statistically significant differences were found between CI, CIID1 and C III in both hypo \& hyper divergent groups regarding the upper symphysial width. The middle symphysial width (B-B1) showed a highly significant difference in hyper-divergent growth between CI and (CIID1- CIII) while in hypo-divergent growth showed a non-significant difference between CI, CIID1 and CIII. The lower symphysial width (Pg-Pg1) showed the greatest value and significant difference in hypo and hyper-divergent CIII than CI and CIID1.(Table1 and 2)

Regarding the distance from $\mathrm{Pg} \perp$ to $\mathrm{Id}-\mathrm{Me}$ line a highly significant difference was found in hypo-divergent growth between CI and CIID1 and in hyper-divergent growth between CIID1 and CIII. C III showed the greatest distance from $\mathrm{Pg} \perp$ to $\mathrm{Id}-\mathrm{Me}$ line in both hypo and hyper divergent groups and the greatest total symphysial height (Id-Me) than CI and CIID1. The anterior inclination angles of the symphysis (Id-B-Pg and $\mathrm{B}-\mathrm{Pg}-\mathrm{Me}$ ) showed the greatest values in CIII malocclusion with highly significant difference between CIID1 and (CI-CIII). (Table1 and 2).

When CI hyper and hypo-divergent groups were compared a significant difference was found between both groups regarding all parameters except upper symphysial width, Id-B distance and Id - B - mp ${ }^{\circ}$ which showed no significant difference (Table 3). A highly significant difference was found between both groups When CIID1 hyper and hypo-divergent groups were compared regarding $\mathrm{Pg} \perp \mathrm{Id} \mathrm{Me}$, lower symphysial width and the anterior inclination angles of the symphysis. (Table 4).

Class III hyper \& hypo-divergent groups showed a highly significant difference was found between both groups regarding B-Pg, Pg-Me and $\mathrm{Pg} \perp \mathrm{Id} \mathrm{Me}$ distance and $\mathrm{Id}-\mathrm{B}-\mathrm{Pg}^{\circ}$ and a significant difference regarding the middle and lower symphysial width. (Table5). 
Table (1): Showing a comparison of linear and angular measurements of hyper-divergent CI, CIID1 and CIII.

\begin{tabular}{|c|c|c|c|c|c|c|}
\hline \multirow{3}{*}{$\begin{array}{l}\text { Linear and } \\
\text { angular } \\
\text { measurements }\end{array}$} & \multicolumn{3}{|c|}{ Hyper-divergent } & \multicolumn{3}{|c|}{ Pvalue } \\
\hline & CI & CIID1 & CIII & \multirow{2}{*}{$\begin{array}{c}\text { CI \& } \\
\text { CIID1 }\end{array}$} & \multirow[b]{2}{*}{ CI \& CIII } & \multirow{2}{*}{$\begin{array}{l}\text { CIID1 \& } \\
\text { CIII }\end{array}$} \\
\hline & Mean \pm SD & Mean \pm SD & Mean \pm SD & & & \\
\hline Id - B & $7.69 \pm 1.06$ & $11.32 \pm 17.41$ & $7.52 \pm 0.73$ & 0.498 & 0.592 & 0.716 \\
\hline $\mathbf{B}-\mathbf{P g}$ & $12.89 \pm 2.85$ & $14.12 \pm 2.04$ & $13.82 \pm 1.32$ & 0.163 & 0.433 & 0.735 \\
\hline Pg-Me & $9.87 \pm 1.30$ & $10.52 \pm 1.9$ & $10.52 \pm 0.98$ & 0.317 & 0.275 & 0.998 \\
\hline Id-Me & $29.24 \pm 4.9$ & $29.80 \pm 3.74$ & $29.98 \pm 2.48$ & 0.877 & 0.718 & 0.524 \\
\hline $\mathrm{Pg} \perp \mathrm{Id} \mathrm{Me}$ & $4.76 \pm 1.83$ & $4.47 \pm 0.55$ & $5.33 \pm 0.82$ & 0.494 & 0.071 & $0.001 * *$ \\
\hline Id - Id1 & $6.36 \pm 0.42$ & $6.20 \pm 0.70$ & $6.03 \pm 0.84$ & 0.492 & 0.281 & 0.598 \\
\hline B - B1 & $10.19 \pm 0.54$ & $8.99 \pm 0.85$ & $8.94 \pm 0.55$ & $0.001 * *$ & $0.002 * *$ & 0.893 \\
\hline Pg - Pg1 & $13.55 \pm 1.42$ & $13.23 \pm 1.17$ & $14.45 \pm 0.97$ & 0.701 & $0.037 *$ & 0.019* \\
\hline B - B1 - Gn ${ }^{\circ}$ & $58.72 \pm 4.2$ & $55.05 \pm 1.12$ & $61.1 \pm 7.21$ & $0.001 * *$ & 0.386 & $0.001 * *$ \\
\hline B - Pg - $-\mathrm{Me}^{\circ}$ & $125.47 \pm 7.1$ & $128.46 \pm 3.64$ & $134.22 \pm 5.05$ & 0.117 & $0.012 *$ & 0.003 *** \\
\hline Id - B - Pg ${ }^{\circ}$ & $159.81 \pm 5.19$ & $153.29 \pm 7.89$ & $162.99 \pm 4.76$ & $0.001 * *$ & 0.209 & $0.005^{* * *}$ \\
\hline B - Pg mp ${ }^{\circ}$ & $67.98 \pm 11.13$ & $65.5 \pm 1.03$ & $65.51 \pm 7.13$ & 0.301 & 0.610 & 0.995 \\
\hline Id - B - mp ${ }^{\circ}$ & $86.50 \pm 5.70$ & $92.13 \pm 9.36$ & $84.67 \pm 7.24$ & 0.078 & 0.558 & 0.065 \\
\hline
\end{tabular}

Table (2): Showing a comparison of linear and angular measurements of hypo-divergent CI, CIID1 and CIII.

\begin{tabular}{|c|c|c|c|c|c|c|}
\hline \multirow{3}{*}{$\begin{array}{l}\text { Linear and } \\
\text { angular } \\
\text { measurements }\end{array}$} & \multicolumn{3}{|c|}{ Hypo-divergent } & \multicolumn{3}{|c|}{ P value } \\
\hline & C1 & CII D1 & CIII & \multirow{2}{*}{ CI \& CIID1 } & \multirow{2}{*}{ CI \& CIII } & \multirow{2}{*}{$\begin{array}{c}\text { CIID1 \& } \\
\text { CIII }\end{array}$} \\
\hline & Mean \pm SD & Mean \pm SD & Mean \pm SD & & & \\
\hline Id - B & $6.41 \pm 1.35$ & $7.19 \pm 1.31$ & $7.63 \pm 1.25$ & 0.173 & $0.001 * *$ & 0.432 \\
\hline B - Pg & $10.48 \pm 2.98$ & $12.01 \pm 2.43$ & $11.39 \pm 2.08$ & 0.207 & 0.304 & 0.521 \\
\hline Pg - Me & $8.84 \pm 1.2$ & $9.01 \pm 1.20$ & $9.45 \pm 0.75$ & 0.736 & 0.083 & 0.280 \\
\hline Id - Me & $24.8 \pm 4.89$ & $23.59 \pm 7.24$ & $26.27 \pm 3.4$ & 0.667 & 0.312 & 0.260 \\
\hline $\mathrm{Pg} \perp \mathrm{Id} \mathrm{Me}$ & $3.57 \pm 1.13$ & $5.08 \pm 0.85$ & $5.69 \pm 0.93$ & $0.001 * *$ & $0.001 * *$ & $0.001 * *$ \\
\hline Id-Id1 & $6.32 \pm 0.70$ & $6.59 \pm 0.53$ & $6.43 \pm 0.55$ & 0.334 & 0.608 & 0.504 \\
\hline B - B1 & $9.78 \pm 0.46$ & $9.86 \pm 0.92$ & $9.66 \pm 0.66$ & 0.756 & 0.519 & 0.546 \\
\hline Pg - Pg1 & $14.92 \pm 1.51$ & $14.65 \pm 1.28$ & $15.64 \pm 0.98$ & 0.658 & 0.106 & $0.046^{*}$ \\
\hline B - B1 - Gn ${ }^{\circ}$ & $54.21 \pm 4.01$ & $53.83 \pm 1.17$ & $50.17 \pm 7.0$ & 0.796 & $0.033^{*}$ & $0.024 *$ \\
\hline $\mathrm{B}-\mathrm{Pg}-\mathrm{Me}^{\circ}$ & $134.71 \pm 7.83$ & $133.1 \pm 3.23$ & $128.58 \pm 5.32$ & 0.581 & $0.011 *$ & $0.039 *$ \\
\hline Id - B - $\mathbf{P g}^{\circ}$ & $155.28 \pm 5.26$ & $133.1 \pm 4.23$ & $157.9 \pm 4.9$ & $0.001 * *$ & 0.131 & $0.001 * *$ \\
\hline B - Pg mp ${ }^{\circ}$ & $56.82 \pm 10.87$ & $67.07 \pm 1.55$ & $58.2 \pm 8.35$ & $0.001 * *$ & $0.001 *$ & 0.711 \\
\hline Id - B - mp ${ }^{\circ}$ & $89.98 \pm 9.53$ & $93.77 \pm 4.39$ & $90.13 \pm 7.94$ & 0.293 & 0.959 & 0.243 \\
\hline
\end{tabular}


Egyptian

Orthodontic Journal

Table (3): Showing a comparison of linear and angular measurements of hyper and Hypo-divergent CI

\begin{tabular}{||c|c|c|c||}
\hline \hline \multirow{2}{*}{$\begin{array}{c}\text { Linear and angular } \\
\text { measurements }\end{array}$} & Hyper-divergent CI & Hypo-divergent C1 & \multirow{2}{*}{ P value } \\
\cline { 2 - 3 } & Mean $\pm \mathrm{SD}$ & Mean $\pm \mathrm{SD}$ & \\
\hline $\mathrm{Id}-\mathrm{B}$ & $7.69 \pm 1.06$ & $6.41 \pm 1.35$ & $\mathbf{0 . 6 9 1}$ \\
\hline $\mathrm{B}-\mathrm{Pg}$ & $12.89 \pm 2.85$ & $10.48 \pm 2.98$ & $\mathbf{0 . 0 3 5 ^ { * }}$ \\
\hline $\mathrm{Pg}-\mathrm{Me}$ & $9.87 \pm 1.30$ & $8.84 \pm 1.2$ & $\mathbf{0 . 0 3 2}$ \\
\hline $\mathrm{Id}-\mathrm{Me}$ & $29.24 \pm 4.9$ & $24.8 \pm 4.89$ & $\mathbf{0 . 0 2 1} *$ \\
\hline $\mathrm{Pg} \perp \mathrm{Id} \mathrm{Me}$ & $4.76 \pm 1.83$ & $3.57 \pm 1.13$ & $\mathbf{0 . 0 2 9} *$ \\
\hline $\mathrm{Id}-\mathrm{Id} 1$ & $6.36 \pm 0.42$ & $6.32 \pm 0.70$ & $\mathbf{0 . 8 4 1}$ \\
\hline $\mathrm{B}-\mathrm{B} 1$ & $10.19 \pm 0.54$ & $9.78 \pm 0.46$ & $\mathbf{0 . 0 3 1} *$ \\
\hline $\mathrm{Pg}-\mathrm{Pg} 1$ & $13.55 \pm 1.42$ & $14.92 \pm 1.51$ & $\mathbf{0 . 0 1 2} *$ \\
\hline $\mathrm{B}-\mathrm{B} 1-\mathrm{Gn}^{\circ}$ & $58.72 \pm 4.2$ & $54.21 \pm 4.01$ & $\mathbf{0 . 0 2 8} *$ \\
\hline $\mathrm{B}-\mathrm{Pg}-\mathrm{Me}^{\circ}$ & $125.47 \pm 7.1$ & $134.71 \pm 7.83$ & $\mathbf{0 . 0 1 1} *$ \\
\hline $\mathrm{Id}-\mathrm{B}-\mathrm{Pg}^{\circ}$ & $159.81 \pm 5.19$ & $155.28 \pm 5.26$ & $\mathbf{0 . 0 2 7} *$ \\
\hline $\mathrm{B}-\mathrm{Pg} \mathrm{mp}^{\circ}$ & $67.98 \pm 11.13$ & $56.82 \pm 10.87$ & $\mathbf{0 . 0 1 0}$ \\
\hline $\mathrm{Id}-\mathrm{B}-\mathrm{mp}^{\circ}$ & $86.50 \pm 5.70$ & $89.98 \pm 9.53$ & $\mathbf{0 . 2 5 3}$ \\
\hline \hline
\end{tabular}

Table (4): Showing a comparison of linear and angular measurements of hyper and Hypo-divergent CIIID1.

\begin{tabular}{||c|c|c|c||}
\hline \hline \multirow{2}{*}{$\begin{array}{c}\text { Linear and angular } \\
\text { measurements }\end{array}$} & Hyper-divergent CIID1 & Hypo-divergent CII D1 & \multirow{2}{*}{ P value } \\
\cline { 2 - 3 } & Mean \pm SD & Mean \pm SD & \\
\hline Id $-\mathrm{B}$ & $11.32 \pm 17.41$ & $7.19 \pm 1.31$ & $\mathbf{0 . 2 4 9}$ \\
\hline $\mathrm{B}-\mathrm{Pg}$ & $14.12 \pm 2.04$ & $12.01 \pm 2.43$ & $\mathbf{0 . 0 2 4}$ \\
\hline $\mathrm{Pg}-\mathrm{Me}$ & $10.52 \pm 1.9$ & $9.01 \pm 1.20$ & $\mathbf{0 . 0 4 4}$ \\
\hline $\mathrm{Id}-\mathrm{Me}$ & $29.80 \pm 3.74$ & $23.59 \pm 7.24$ & $\mathbf{0 . 0 1 5}^{*}$ \\
\hline $\mathrm{Pg} \perp \mathrm{Id} \mathrm{Me}$ & $4.47 \pm 0.55$ & $5.28 \pm 0.85$ & $\mathbf{0 . 0 0 5} * *$ \\
\hline $\mathrm{Id}-\mathrm{Id} 1$ & $6.20 \pm 0.70$ & $6.59 \pm 0.53$ & $\mathbf{0 . 1 6 4}$ \\
\hline $\mathrm{B}-\mathrm{B} 1$ & $8.99 \pm 0.85$ & $9.86 \pm 0.92$ & $\mathbf{0 . 0 2 2} *$ \\
\hline $\mathrm{Pg}-\mathrm{Pg} 1$ & $13.23 \pm 1.17$ & $14.65 \pm 1.28$ & $\mathbf{0 . 0 0 8} * *$ \\
\hline $\mathrm{B}-\mathrm{B} 1-\mathrm{Gn}^{\circ}$ & $55.05 \pm 1.12$ & $53.83 \pm 1.17$ & $\mathbf{0 . 0 1 4}$ \\
\hline $\mathrm{B}-\mathrm{Pg}-\mathrm{Me}^{\circ}$ & $128.46 \pm 3.64$ & $133.1 \pm 3.23$ & $\mathbf{0 . 0 0 4} * *$ \\
\hline $\mathrm{Id}-\mathrm{B}-\mathrm{Pg}^{\circ}$ & $153.29 \pm 7.89$ & $133.1 \pm 4.23$ & $\mathbf{0 . 0 0 1} * *$ \\
\hline $\mathrm{B}-\mathrm{Pg} \mathrm{mp}^{\circ}$ & $65.5 \pm 1.03$ & $67.07 \pm 1.55$ & $\mathbf{0 . 0 0 3} * *$ \\
\hline $\mathrm{Id}-\mathrm{B}-\mathrm{mp}^{\circ}$ & $92.13 \pm 9.36$ & $93.77 \pm 4.39$ & $\mathbf{0 . 6 2 7}$ \\
\hline \hline
\end{tabular}

Volume 49 - June 2016 
Egyptian

Orthodontic Journal

Table (5): Showing a comparison of linear and angular measurements of hyper and Hypo-divergent CIII.

\begin{tabular}{|c|c|c|c|}
\hline \multirow{2}{*}{$\begin{array}{l}\text { Linear and angular } \\
\text { measurements }\end{array}$} & Hyper-divergent CIII & Hypo-divergent CIII & \multirow{2}{*}{$P$ value } \\
\hline & Mean \pm SD & Mean \pm SD & \\
\hline $\mathrm{Id}-\mathrm{B}$ & $7.52 \pm 0.73$ & $7.63 \pm 1.25$ & 0.977 \\
\hline $\mathrm{B}-\mathrm{Pg}$ & $13.82 \pm 1.32$ & $11.39 \pm 2.08$ & $0.009 * *$ \\
\hline $\mathrm{Pg}-\mathrm{Me}$ & $10.52 \pm 0.98$ & $9.45 \pm 0.75$ & $0.009 * *$ \\
\hline $\mathrm{Id}-\mathrm{Me}$ & $29.98 \pm 2.48$ & $26.27 \pm 3.4$ & $0.017 *$ \\
\hline $\mathrm{Pg} \perp \mathrm{Id} \mathrm{Me}$ & $3.33 \pm 0.82$ & $4.49 \pm 0.93$ & $0.009 * *$ \\
\hline Id - Id 1 & $6.03 \pm 0.84$ & $6.43 \pm 0.55$ & 0.166 \\
\hline B - B1 & $8.94 \pm 0.55$ & $9.66 \pm 0.66$ & $0.019 *$ \\
\hline $\mathrm{Pg}-\mathrm{Pg} 1$ & $14.45 \pm 0.97$ & $15.64 \pm 0.98$ & $0.014 *$ \\
\hline $\mathrm{B}-\mathrm{B} 1-\mathrm{Gn}^{\circ}$ & $61.1 \pm 7.21$ & $50.17 \pm 7.0$ & $0.002 * *$ \\
\hline $\mathrm{B}-\mathrm{Pg}-\mathrm{Me}^{\circ}$ & $134.22 \pm 5.05$ & $128.58 \pm 5.32$ & $0.027^{*}$ \\
\hline $\mathrm{Id}-\mathrm{B}-\mathrm{Pg}^{\circ}$ & $162.99 \pm 4.76$ & $157.9 \pm 4.9$ & $0.031 * *$ \\
\hline $\mathrm{B}-\mathrm{Pg} \mathrm{mp}^{\circ}$ & $65.51 \pm 7.13$ & $68.2 \pm 8.35$ & 0.384 \\
\hline $\mathrm{Id}-\mathrm{B}-\mathrm{mp}^{\circ}$ & $84.67 \pm 7.24$ & $90.13 \pm 7.94$ & 0.142 \\
\hline
\end{tabular}

\section{DISCUSSION}

The MS morphology is an important factor in evaluation of diagnosis and treatment planning. A wider symphysis may be more compatible with more protrusion of the incisor. ${ }^{(23)}$

The sample age in the present study ranged from 11 to 13 year which may present a bias in the study. An attempt was made to overcome the bias of different stages of puberty with the evaluation of skeletal maturation stages of the subjects using hand-wrist radiographs which were matched in all groups. ${ }^{(31)}$ 
Egyptian

Orthodontic Journal

This study was conducted on 120 females sample and the male not included because Buschang et al $^{(32)}$ stated that sexual dimorphism in mandibular size favouring males could be temporarily confounded in early years by the earlier growth spurt of females, given that male proportions are larger than their female counterparts. ${ }^{(33,34)}$

Dento-alveolar compensation is usually a good camouflage for the underlying antero-posterior skeletal discrepancy. ${ }^{(35,36)}$ Changes in the inclination of the lower incisors to compensate for the skeletal discrepancy in different AP relationships might cause surface remodeling of MS, affecting its morphology ${ }^{(37)}$ Accordingly, the present research looked at some of the characteristics of MS in the three AP relationships .

The sample was divided into hyper and hypo-divergent according to SN to Mp because previous studies showed that, individuals with a vertical growth pattern have a longer and narrower symphysis; in those with horizontal growth it is shorter and wider. ${ }^{(38,39)}$

In accordance with our results regarding the MS height Elcin E and Fidan A $2012^{(40)}$ found that the MS height was greater in the hyperdivergent group than in the hypo-divergent groups but was not statistically significant. MS width was higher in the hypo-divergent group than in the hyper-divergent group

Our study was based on both sagittal and vertical jaw relationship measurements taken directly from CT of the MS in the midline and came in accordance with Swasty et al. ${ }^{(34)}$ as they showed similar finding for heights of the MS in their CBCT study and demonstrated longer MS in long faces compared with subjects with average and short faces

Swasty et al. ${ }^{(34)}$ also stated that short face group had wider MS compared with those of long- and average face groups and revealed that the widths of the MS are similar and statistically insignificant for all groups on the other hand the present study only upper and middle MS widths showed no significant difference between CI,CII and CIII in both hypo and hyper divergent groups. Similar results were obtained from CBCT supported the claims that the total thickness of the MS is greater in short-face subjects as opposed to their long-face counterparts ${ }^{(41)}$ 
Egyptian

Orthodontic Journal

According to Björk, ${ }^{(36)}$ in high-angle cases, the pronounced apposition below the MS and the anterior part of the mandible produces an anterior rounding which coincide with the findings of the present study. Similar findings with our results were found by Ulaş Öz and Meliha Rübendüz $2013^{(42)}$ where no significant differences for the measurement of upper (Id-Id1) and middle (B-B1) width of the MS, however the lower MS width measurement (Pg-Pg1) was statistically shorter in hyper-divergent Class II subjects compared with all other groups.

The decrease in lower alveolar symphysis width may be related to mentalis muscle hyperactivity, and such relationship is more obvious in patients with Class II skeletal pattern than class I, these findings came in accordance with Pichaya $2014^{(43)}$ who reported similar findings.

An association was found between the symphysial inclination and vertical dimension. The MS was inclined more forward according to mandibular base in all Class II subjects than control. The angle between mandibular plane and the symphysis, were greater in all Class II groups compared with Class I group also it has been reported that a greater inclination of the MS is associated with an anterior growth direction and a smaller inclination is often consistent with hyper-divergent patterns. ${ }^{(21,44)}$

Also, the results of the study were in agreement with Handelman ${ }^{(12)}$ and Beckmann ${ }^{(45)}$ who reported that hyper-divergent patients present a thinner MS and a thinner alveolar ridge in the anterior region of the mandible, compared to the other facial patterns.

In the present study, the MS in hypo-divergent facial type was found to be associated with short height and large depth, these results are consistent with the findings of Aki et al ${ }^{(23)}$ and Ricketts ${ }^{(21)}$ who found a thick MS to be associated with an anterior growth direction. Sassouni $^{(46)}$ and Bjork $^{(22)}$ have found a tendency toward backward mandibular rotation to be associated with the pronounced apposition below the MS with more overall concavity of the lower mandibular border.

Volume 49 - June 2016 
Egyptian

Orthodontic Journal

The linear distances and angular measurements that expressed the vertical dimension of MS and the area of MS were largest in the Class III group compared to the Class I and Class II groups; these findings came in accordance with several studies who reported a larger mandible in the Class III. ${ }^{(47-49)}$

The convexity of the contour of the skeletal part of MS was evaluated by angular and linear parameters. The angle B-Pg-Me and the perpendicular distance from Pg to Id-Me line, respectively. Although the angular measurement was smaller in the Class III hypo-divergent group than in the Class II hypo-divergent group with significant difference between both groups; these findings came partially in accordance with Mouakeh $2001^{(47)}$ who reported no significant difference between both groups.

In accordance with Molina $2013^{(50)}$ the vertical facial pattern is a significant factor in MS morphology, so short-faced Class III patients have a widened alveolar bone. However, for long-faced Class III, natural compensation elongates the symphysis. Similarly with our results Susan et al 2014 ${ }^{(51)}$ reported that Class III subjects showed greater inclination of the alveolar part of the MS relative to the mandibular plane than did Class I and Class II subjects.

In the present study, the higher difference in the inclination of the MS in Class III when compared with Class I and Clas II may be attributed to compensatory inclinations of the mandibular incisors in mandibular prognathism for skeletal imbalances between the jaws. This inclination had a considerable effect on the inclination of the MS a similar conclusions was reported by many earlier studies ${ }^{(52)}$

In contrast with our results $\mathrm{Nu}^{\prime}$ Molina- et al 2013(53) reported insignificant differences with regard to the MS dimensions between the Class I and Class III samples and within the Class III this contradiction may be due to difference in methodology and sample size.

\section{CONCLUSIONS}

A significant difference was found between MS dimensions and different antero-posterior and vertical growth pattern of the face. Hyper-divergent growth has a longer and narrower MS than hypo-divergent growth. 
Egyptian

Orthodontic Journal

\section{REFERENCES}

1. Buschang PH, Julien K, Sachdeva R, Demirjian A. Childhood and pubertal growth changes of the human symphysis. Angle Orthod. 1992; 62:203-10.

2. Hoenig JF. Sliding osteotomy genioplasty for facial aesthetic balance: 10 years of experience. Aesthetic Plast Surg. 2007; 31:384-91.

3. Nojima K, Nakakawaji K, SakamotoT, Isshiki Y. Relationships between mandibular symphysis morphology and lower incisor inclination in skeletal Class III malocclusion requiring orthognatic surgery. Bull Tokyo Dent. Coll 1998; 39:175-81.

4. Steiner CC. Cephalometric in clinical practice. Angle Orthod 1959; 29:8-29.

5. Gould SJ. The exaptive excellence of spandrels as a term and prototype. Proc Natl Acad Sci USA. 1997; 94:10750-55.

6. Sherwood RJ, Hlusko LJ, Duren DL, Emch VC, Walker A. Mandibular symphysis of large-bodied hominoids. Hum Biol. 2005; 11:735-59.

7. Beecher RM. Evolution of the mandibular symphysis in Notharctinae (Adapidae Primates). Int J Primatol. 1983; 4: 99-112.

8. Daegting DJ, Hylander WL. Biomechanics of torsion in the human mandible. Am J Phys Anthropol. 1998; 105:73-87.

9. Perera PSG. Rotational growth and incisor compensation. Angle Orthod 1987; 57:39-49.

10. Chung CJ, Jung S, Baik HS. Morphological characteristics of the symphyseal region in adult skeletal Class III crossbite and openbite malocclusions. Angle Orthod 2008; 78:38-43.

11. Arnett GW, Jelic JS, Kim J, Cummings DR, Beress A, Worley CM Jr et al. Soft tissue cephalometric analysis: diagnosis and treatment planning of dentofacial deformity. Am J Orthod Dentofacial Orthop. 1999; 116:239-53. 
Egyptian

Orthodontic Journal

12. Handelman C.S. The anterior alveolus: its importance in limiting orthodontic treatment and its infl uence on the occurrence of iatrogenic sequelae. Angle Orthod. 1996; 66:95-110

13. Mulie RM, Hoeve AT. The limitations of tooth movement within the symphysi, studied with laminography and standardized occlusal films. J Clin Orthod. 1976; 10:882-93.

14. Scavone H, Zahn-Silva W, do Valle-Corotti KM, Nahgs AC. Soft tissue profile in white Brazilian adults with normal occlusions and well-balanced faces. Angle Orthod. 2008; 78:58-63.

15. Baccetti T, Stahl F, McNamara JA Jr. Dentofacial growth changes in subjects with untreated Class II malocclusion from late puberty through young adulthood. Am J Orthod Dentofacial Orthop 2009; 135: $148-54$.

16. McNamara JA Jr. Components of class II malocclusion in children 8-10 years of age. Angle Orthod 1981; 51: 177-202.

17. Ishii N, Deguchi T, Hunt NP. Craniofacial morphology of Japanese girls with Class II division 1 malocclusion. J Orthod 2001; 28: 211-15.

18. Schudy FF. Vertical growth versus antero-posterior growth as related to function and treatment. Angle Orthod 1964; 34: 75-93.

19. Jacob HB, Buschang PH. Vertical craniofacial growth changes in French-Canadians between 10 and 15 years of age. Am J Orthod Dentofacial Orthop 2011; 139: 797-805

20. Björk A, Skieller V. Normal and abnormal growth of the mandible. A synthesis of longitudinal cephalometric implant studies over a period of 25 years. Eur J Orthod 1983; 5: 1-46.

21. Ricketts RM. Cephalometric Synthesis. Am J Orthod 1960; 46: 647-673.

22. Bjork A. Prediction of mandibular growth rotation. Am J Orthod. 1969; 55:585-99.

23. Aki T, Nanda RS, Currier GF, Nanda SK. Assessment of symphysis morphology as a predictor of the direction of mandibular growth. Am J Orthod Dentofacial Orthop 1994; 106: 60-69. 
Egyptian

Orthodontic Journal

24. Betzenberger D, Ruf S, Pancherz H. The compensatory mechanism in high-angle malocclusions: A comparison of subjects in the mixed and permanent dentition. Angle Orthod 1999; 69: 27-32.

25. Proffit WR, Fields HW, Sarver DM. Contemporary Orthodontics, 4th ed. St Louis, Mo: Elsevier; 2007.

26. Sugawara, J. and Mitani, H. Facial growth of skeletal Class III malocclusion and the effects, limitations, and long-term dentofacial adaptations to chincap therapy, Seminars in Orthodontics. 1997; 3: 244-54.

27. Karlsen, A. T. 1998 Longitudinal changes in Class I subjects with moderate mandibular skeletal protrusion, Angle Orthodontist, 68, 431-38.

28. Kerr,W. J. and Ten Have T. R. Mandibular position in Class III malocclusion, British Journal of Orthodontics. 1988; 15: 241-45.

29. Kerr,W. J., Miller, S., Ayme, B. and Wilhelm, N. Mandibular form and position in 10-year-old boys, American Journal of Orthodontics and Dentofacial Orthopedics. 1994; 106: 115-20.

30. Tweed CH. A philosophy of orthodontic treatment. Am J Orthod 1945; 31:74-103.

31. Oz U, Rubenduz M. Craniofacial differences between skeletal Class II and Class I malocclusions according to vertical classification. J Stomat Occ Med 2011; 4: 105-11.

32. Buschang PH, Nass GG, Walker GF. Principal components of craniofacial growth for white Philadelphia males and females between 6 and 22 years of age. Am J Orthod 1982; 82: 508-12.

33. Baccetti T, Reyes BC, McNamara JA Jr. Gender differences in Class III malocclusion. Angle Orthod 2005; 75: 510-20.

34. Swasty D, Lee J, Huang JC, Maki K, Gansky SA, Hatcher D et al. Cross-sectional human mandibular morphology as assessed in vivo by cone-beam computed tomography in patients with different vertical facial dimensions. Am J Orthod Dentofacial Orthop 2011; 139: e377-89. 
Egyptian

Orthodontic Journal

35. Solow B. The dentoalveolar compensatory mechanism: background and clinical implications. Br J Orthod. 1980; 7: 145-61.

36. Bjo"rk A. Sutural growth of the upper face studied by the implant method. Acta Odontol Scand. 1966; 24:109-27.

37. Yu Q, Pan XG, Ji GP, Shen G. The association between lower incisal inclination and morphology of the supporting alveolar bone a cone-beam CT study. Int J Oral Sci. 2009; 1:217-23.

38. Haskell BS. The human chin and its relationship to mandibular morphology. Angle Orthod 1979; 49:153-66.

39. Wehrbein H, Bauer W, Diedrich P. Mandibular incisors, alveolar bone, and symphysis after orthodontic treatment. A retrospective study. Am J Orthod Dentofacial Orthop 1996; 110:239-46.

40. Elcin Esenlik and Fidan Alakus Sabuncuoglu Alveolar and symphysis regions of patients with skeletal class II division 1 anomalies with different vertical growth patterns. Eur J Dent.2012; 6:123-32.

41. Gracco A., Luca L., Bongiorno M.C., Siciliani G. Computed tomography evaluation of mandibular incisor bony support in untreated patients. Am J Orthod Dentofacial Orthop. 2010; 138:179-87.

42. Ulaş Öz and Meliha Rübendüz The differences of symphysis morphology in class II malocclusions with different vertical growth pattern. Clinical dentistry and research. 2013; 37: 3-12

43. Pichaya P, Ratthakorn S, Apiwat $\mathrm{CH}$, Chidsanu $\mathrm{CH}$. Relationship between mentalis muscle hyperactivity and mandibular symphysis morphology in skeletal Class I and II patients. Orthodontic Waves. 2014; $73: 130-35$

44. Mangla R, Singh N, Dua V, Padmanabhan P, Khanna M. Evaluation of mandibular morphology in different facial types. Contemp Clin Dent. 2011; 2: 200-206.

45. Beckmann S.H., Kuitert R.B., Prahl A.B., Segner D., The R.P., Tuinzing D.B. Alveolar and skeletal dimensions associated with lower face height. Am J Orthod Dentofacial Orthop. 1998 May; 113:498-506. 
46. Sassouni V. A classification of skeletal facial types. Am J Orthod. 1969; 55:109-23.

47. Mouakeh M. Cephalometric evaluation of craniofacial pattern of Syrian children with Class III malocclusion. Am J Orthod Dentofacial Orthop. 2001; 119:640-49.

48. Reyes BC, Baccetti T, McNamara JA Jr. An estimate of craniofacial growth in Class III malocclusion. Angle Orthod. 2006; 76:577-84.

49. Wolfe SM, Araujo E, Behrents RJ, Buschang PH. Craniofacial growth of Class III subjects six to sixteen years of age. Angle Orthod. 2011; 81:211-16.

50. Molina B, Perez J, Mir C and Puigdollers A. Lower incisor dento-alveolar compensation and symphysis dimensions among Class I and III malocclusion patients with different facial vertical skeletal patterns. Angle Orthod. 2013; 83: 948-55

51. Susan N. Al-Khateeba; Emad F. Al Maaitahb; Elham S. Abu Alhaijac; Serene A. Badrand Mandibular symphysis morphology and dimensions in different anteroposterior jaw relationships.Angle Orthod. 2014; 84:304-309.

52. Ishikawa $H$, Nakamura $S$, Iwasaki $H$, Kitazawa $S$, Tsukada $H$, Chu $S$. Dentoalveolar compensation in negative overjet cases. Angle Orthod. 2000; 70:145-8.

53. Nu'ria Molina-Berlangaa; Jaume Llopis-Perezb; Carlos Flores-Mirc; Andreu Puigdollersd Lower incisor dentoalveolar compensation and symphysis dimensions among Class I and III malocclusion patients with different facial vertical skeletal patterns.Angle Orthod. 2013; 83:948-55. 